\title{
Proton MR spectroscopic imaging of human glioblastomas at 1.5 Tesla
}

\author{
Petra Hnilicová ${ }^{1}$, Romana Richterová ${ }^{2}$ Ema Kantorová ${ }^{3}$, Michal Bittšanský $^{1}$, Eva Baranovičová ${ }^{1}$ \\ and Dušan Dobrota ${ }^{4}$ \\ ${ }^{1}$ Division of Neurosciences at Biomedical Center Martin, Jessenius Faculty of Medicine in Martin, Comenius University in \\ Bratislava, Martin, Slovakia \\ ${ }^{2}$ Clinic of Neurosurgery, Jessenius Faculty of Medicine in Martin, Comenius University in Bratislava, Martin, Slovakia \\ ${ }^{3}$ Clinic of Neurology, Jessenius Faculty of Medicine in Martin, Comenius University in Bratislava, Martin, Slovakia \\ ${ }^{4}$ Department of Medical Biochemistry, Jessenius Faculty of Medicine in Martin, Comenius University in Bratislava, Martin, Slovakia
}

\begin{abstract}
In this study we evaluated clinical feasibility of proton magnetic resonance spectroscopy metabolite mapping $\left({ }^{1} \mathrm{H}\right.$ MRSI) by using 1.5 Tesla MR-scanner in 10 patients with high-grade glioblastoma. In vivo ${ }^{1} \mathrm{H}$ MRSI performed with a relatively short scan time of 20 minutes enabled to obtain comprehensive information about metabolic changes in glioblastoma and adjacent tissues namely in the peritumoral edema, in the middle and solid part of the tumor, and in the normal-appearing brain tissue. Spectroscopically it was possible to identify initiation of neuronal cell death in the solid tumorous tissue via decreased $\mathrm{N}$-acetyl-aspartate to creatine ratio $(\downarrow \mathrm{tNAA} / \mathrm{tCr})$ and expanding carcinogenesis reflected in elevated choline ratios ( $\uparrow \mathrm{tCho/tCr}$ and tCho/tNAA). We showed also the central necrosis of glioblastoma accompanied by the tissue hypoxia, which were apparent as increased lactate and lipids ratios ( $\uparrow \mathrm{Lac} / \mathrm{tCr}$ and lip/Lac). Metabolic changes were noticeable also in the peritumoral area, showing the glioblastoma infiltration into the surrounding tissues. In intracranial tumors, ${ }^{1} \mathrm{H}$ MRSI performed on 1.5 Tesla field strength was sufficient to provide information about the stage of carcinogenesis, tumor expansion or necrotization and thus it could be considered as a useful diagnostic tool in oncology.
\end{abstract}

Key words: ${ }^{1} \mathrm{H}$ MRS - Brain — Glioblastoma - Carcinogenesis

\section{Introduction}

Proton magnetic resonance spectroscopy $\left({ }^{1} \mathrm{H}\right.$ MRS $)$ provides non-invasive insight into the tissue metabolism, and allows information to be obtained about tumorous pathophysiology, i.e. about tumor expansion, its carcinogenesis or necrotization (McKnight and Wladman 2010; Wijnen 2010). The common metabolites detected in the intracranial tumors by ${ }^{1} \mathrm{H}$ MRS at 1.5 Tesla field strength are $\mathrm{N}$-acetylaspartate with $\mathrm{N}$-acetylaspartyl-glutamate (tNAA), choline-containing (tCho) and creatine-containing (tCr) compounds, lactate (Lac), and lipids (lip) (Callot et al. 2008; Barker 2010; Wijnen 2010). Since the tNAA is synthesized in neuronal mitochondria it is regarded as a marker of neuronal viability and function (Soares and Law 2009; Barker 2010). However, tNAA is not a sufficiently

Correspondence to: Dušan Dobrota, Department of Medical Biochemistry, Jessenius Faculty of Medicine in Martin, Comenius University in Bratislava, Malá Hora 11161/4D, 03601 Martin, Slovakia E-mail: dusan.dobrota@jfmed.uniba.sk specific marker for glioblastomas (Laprie et al. 2008; Horska and Barker 2010), its decline reliably indicates the loss of healthy neurons in the tumor-affected brain tissue (Glunde and Bhujwalla 2011; Kao et al. 2013). To the tCho signal mainly phosphocholine contributes, and in a lesser extent glycerophosphocholine, free choline, and acetylcholine (Horska and Barker 2010; McKnight and Wladman 2010). Since the phosphocholine is the precursor of membrane phospholipids synthesis (Solivera et al. 2009; Ha et al. 2013), tCho is considered to be the most useful MRS parameter reflecting higher cellular proliferation and tumor carcinogenesis (Guillevin et al. 2008; Housni and Boujraf 2013). The concentration of free creatine and phosphocreatine, detected as a joint peak $\mathrm{tCr}$, has the most stable value among ${ }^{1} \mathrm{H}$ MRS detectable metabolites and thus it is usually used as a reference for relative metabolite quantification (Soares and Law 2009; Barker 2010). For ${ }^{1} \mathrm{H}$ MRS, Lac due to its low concentration in the brain under physiological conditions is almost unnoticeable (Soaresand Law 2009; Kumar et al. 2012). Therefore its increased level is considered to be an unequivocal indicator of pathological 
processes, revealing tissue necrosis, lipogenesis or switch from aerobic to anaerobic glycolysis (Callot et al. 2008; Marie and Shinjo 2011; Housni and Boujraf 2013). Finally, ${ }^{1} \mathrm{H}$ MRS enables to quantify lipids, i.e. triacylglycerols and cholesterol esters accumulated in lipid droplets (Opstad et al. 2008; Walther and Forese 2009). The exact role of lipid droplets in the brain is not fully understood, but they are believed to be reservoirs of fatty acids arising as a waste product during degradation of cellular membranes in the necrotic tissue (Toyooka et al. 2008; Walther and Forese 2009; Delikatny et al. 2011) as well as in tumor cells, in which the apoptosis has been initiated (Opstad et al. 2008; Glunde and Bhujwalla 2011). Although the evidence of spectroscopically detectable differences of

Table 1. ${ }^{1} \mathrm{H}$ MRS metabolite ratios in selected brain areas of patiens with glioblastoma

\begin{tabular}{|c|c|c|c|c|}
\hline & & \multicolumn{3}{|c|}{ Wilcoxon test } \\
\hline & & solid & edema & healthy \\
\hline \multicolumn{5}{|c|}{$t N A A / t C r$} \\
\hline middle & $0.689 \pm 0.261$ & $* *$ & $* *$ & $* *$ \\
\hline solid & $1.088 \pm 0.142$ & - & NS & $* *$ \\
\hline edema & $1.107 \pm 0.126$ & - & - & $* *$ \\
\hline healthy & $2.161 \pm 0.303$ & KW: & $* * *$ & \\
\hline \multicolumn{5}{|c|}{ tChol/tNAA } \\
\hline middle & $1.245 \pm 0.670$ & * & $* *$ & $* *$ \\
\hline solid & $0.729 \pm 0.126$ & - & $* *$ & $* *$ \\
\hline edema & $0.543 \pm 0.131$ & - & - & $* *$ \\
\hline healthy & $0.148 \pm 0.035$ & KW: & $* * *$ & \\
\hline \multicolumn{5}{|c|}{$t$ Chol/tCr } \\
\hline middle & $0.731 \pm 0.242$ & NS & NS & ** \\
\hline solid & $0.788 \pm 0.152$ & - & * & $* *$ \\
\hline edema & $0.601 \pm 0.161$ & - & - & $* *$ \\
\hline healthy & $0.314 \pm 0.062$ & KW: & $* * *$ & \\
\hline \multicolumn{5}{|c|}{$\mathrm{Lac} / \mathrm{tCr}$} \\
\hline middle & $5.602 \pm 5.856$ & NS & NS & * \\
\hline solid & $5.774 \pm 5.597$ & - & NS & * \\
\hline edema & $2.529 \pm 1.971$ & - & - & NS \\
\hline healthy & $0.998 \pm 0.763$ & KW: & * & \\
\hline \multicolumn{5}{|c|}{ Lip/Lac } \\
\hline middle & $33.587 \pm 67.932$ & * & * & * \\
\hline solid & $2.187 \pm 2.855$ & - & NS & NS \\
\hline edema & $1.912 \pm 1.785$ & - & - & NS \\
\hline healthy & $0.837 \pm 1.428$ & KW: & * & \\
\hline
\end{tabular}

Metabolites ratios (mean \pm standard deviation) evaluated in the middle and solid part of the tumor, in the peritumoral edema, and in the apparent healthy brain tissue of the patients with glioblastoma $(n=10)$. Shown are the statistical differences between the couples of selected brain areas obtained using the Wilcoxon test and between all selected areas, which were calculated by the Kruskal-Wallis test (KW). The level of significance was intended as follows: ${ }^{\star} 0.01 \leq p<$ 0.05 significant; ${ }^{* *} 0.001 \leq p<0.01$ very significant; ${ }^{* * *} p<0.001$ extremely significant. NS, non-significant $(p>0.05)$. tNAA, total $\mathrm{N}$-acetylaspartate; $\mathrm{Cr}$, creatine; tCho, choline; Lac, lactate; lip, lipids. metabolite concentrations in the tumors compared to the normal brain tissue (McKnight and Wladman 2010; Kumar et al. 2012; Pinker et al. 2012) was demonstrated, the clinical application of ${ }^{1} \mathrm{H}$ MRS for examination of intracranial tumors has until recently been somewhat limited. One reason for this may be the tissue heterogeneity and relatively low MR sensitivity for ${ }^{1} \mathrm{H}$ MRS at 1.5 Tesla field strength (Kornienko and Pronin 2009; Barker 2010). Therefore, the single voxel spectroscopy with larger voxels had to be used $\left(\sim 4-20 \mathrm{~cm}^{3}\right)$ making impossible to study spatial metabolite changes within the tissue (Wijnen 2010; Housni and Boujraf 2013). In the present study, the ${ }^{1} \mathrm{H}$ MRS was performed by $3 \mathrm{D}$ chemical shift imaging sequence $\left({ }^{1} \mathrm{H} \mathrm{MRSI}\right)$, enabling metabolite mapping of the tissue with relatively small voxel volume of $0.5 \mathrm{~cm}^{3}$ and in a reasonable scan time of 20 minutes. We aimed this study to evaluate the clinical feasibility of ${ }^{1} \mathrm{H}$ MRSI mapping of spatial metabolic changes in glioblastomas, despite its application in 1.5 Tesla field strength.

\section{Materials and Methods}

\section{Patients}

All measurements in this study were carried out in compliance with the local institutional medical ethics committee and after obtaining the written informed consent from all project participants. The MRS study was performed on 10 patients (mean age: $64 \pm 8$ years; 6 males and 4 females) who had suspected intracranial tumorous lesions detected on MRI. All patients underwent MRS examination prior to the clinical as well as surgical treatment and subsequent histological analyses. In all cases grade IV glioblastomas were confirmed.

\section{Data measurement and analysis}

All investigations were performed on a clinical 1.5 Tesla whole-body MR system Magnetom Symphony (Siemens, Erlangen, Germany). For volume selection and signal detection we used a proton 8-channel head coil from Siemens.

The MRI protocol included multi-slice $\mathrm{T}_{2}$-weighted MRI in three orthogonal planes $(2 \mathrm{D}$ spin echo, repetition time (TR)/echo time $(\mathrm{TE})=3000 / 51 \mathrm{~ms}, 24$ slices with a thickness of $3.5 \mathrm{~mm}$, field of view (FOV) of $245 \times 280 \mathrm{~mm}^{2}$ ). For ${ }^{1} \mathrm{H}$ MRS, 3D chemical shift imaging (CSI) sequence was carried out using a point resolved spectroscopy (PRESS) in an axial plane with TR/TE $=1500 / 135 \mathrm{~ms}$ and FOV of $100 \times 95 \times 80 \mathrm{~mm}^{3}$. The volume of interest (VOI) was usually $70 \times 80 \times 50 \mathrm{~mm}^{3}$ with a slight variation depending on the size and location of the tumor. During measurement we used the CSI matrix of $12 \times 12 \times 10$ voxels, interpolated to $16 \times 16 \times 16$ voxels with the nominal voxel size $8.3 \times 7.9 \times 8.0 \mathrm{~mm}^{3}$. The total acquisition time did not exceed 20 minutes. 


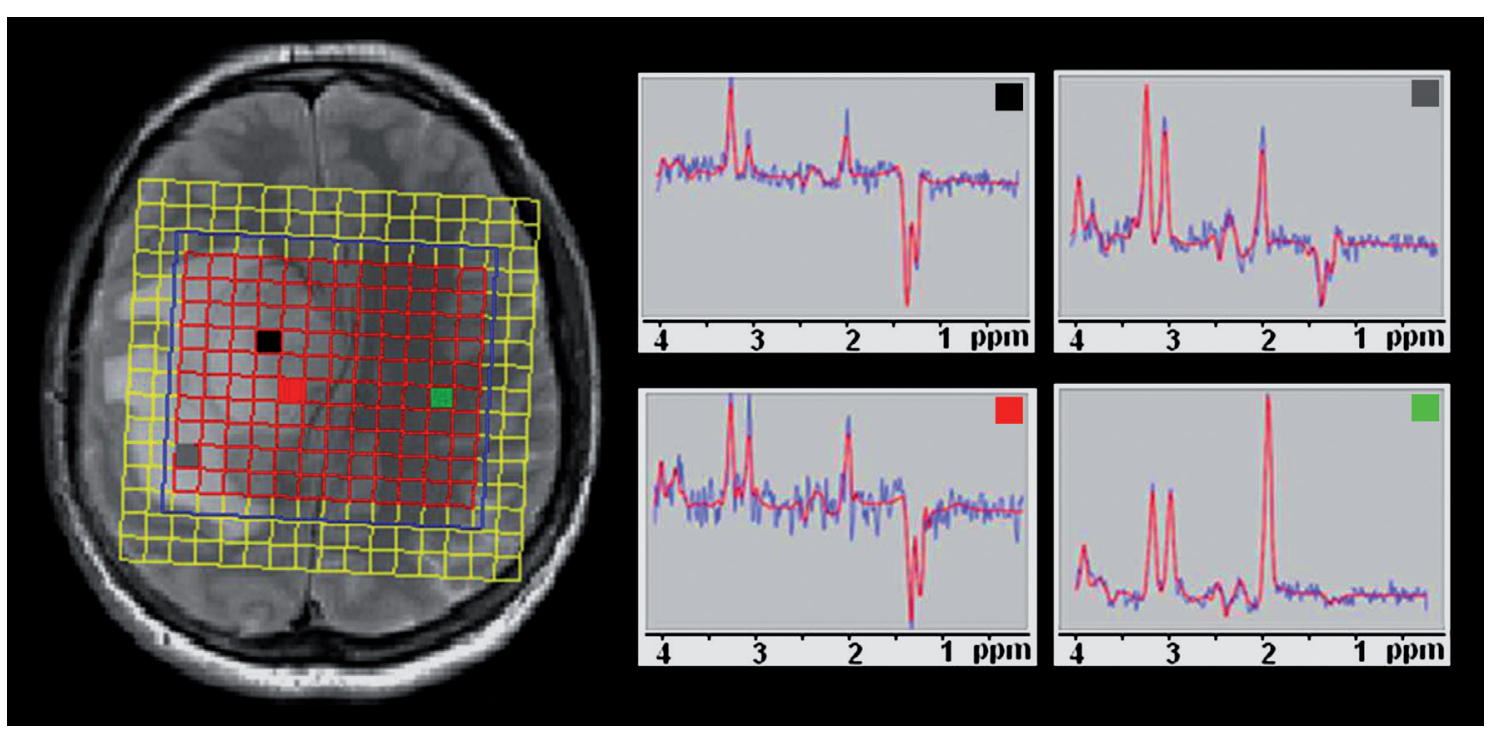

Figure 1. Evaluation of ${ }^{1} \mathrm{H}$ MR spectra in selected brain voxels in glioblastoma. The voxels location based on the overlapping of the $\mathrm{T}_{2}$-weighted MRI with the CSI matrix: voxel in the centre of the tumor mass (black voxel); voxel in the solid tumor part near its boundary (red voxel); voxel in the peritumoral edema (grey voxel); and voxel in a normal appearing brain tissue (green voxel). All data were measured at 1.5 Tesla using the 8-channel head coil and were evaluated by LCModel and jSIPRO.

All MR spectra were analysed with a graphical user interface for automatic data processing jSIPRO (Version 1.0, Filip Jiru \& Antonin Skoch, IKEM, Prague, Czech Republic) which employed LCModel software (Version 6.2-1L, S.Provencher, LCModel, Oakville, ON, Canada). Based on the overlapping of multi-slice $\mathrm{T}_{2}$-weighted MRI with the spectroscopic CSI matrix, it was possible to evaluate the MR spectra in following four selected brain tissue areas. One voxel was chosen in the centre of the tumor mass, situated at least three voxels away from the tumor boundary. The second one was selected in the solid part of the tumorous lesion, near the edge of the tumor with respect to a minimal distance one voxel from its margin. The third voxel was localised in the peritumoral edema, remote from the tumor boundary of at least two voxels. The last one was located in a normal appearing brain tissue on $\mathrm{T}_{2}$-weighted MRI, with a distance of at least two voxels away from the pathological areas (Fig. 1).

From each ${ }^{1} \mathrm{H}$ MR spectra we obtained the integrals of following metabolites: tNAA, tCho, tCr, Lac and lip (with a chemical shift of $0.9 \mathrm{ppm}, 1.3 \mathrm{ppm}$ and $2.0 \mathrm{ppm}$ ). The metabolite ratios (i.e. tCho/tNAA, tNAA/tCr, tCho/tCr, Lac/ tCho and lip/Lac) were finally calculated.

The mean values of all metabolite ratios were examined between the couples of selected brain tissue areas using the Wilcoxon test and between all four selected areas by KruskalWallis test. Using the Spearman correlation analysis we researched the dependency of $\mathrm{tCho} / \mathrm{tCr}$ and $\mathrm{tNAA} / \mathrm{tCr}$ with respect to selected brain tissue area. The statistical analysis was performed by using the SPSS software package (Version
15.0, Chicago, IL, USA). A $p$ value of less than 0.05 was considered significant, taking the level of significance intended as follows: $0.01 \leq p<0.05$ significant $\left({ }^{*}\right) ; 0.001 \leq p<0.01$ very significant $\left.{ }^{* *}\right)$; and $p<0.001$ extremely significant ${ }^{* * *}$ ).

\section{Results}

Among the all selected brain tissue areas in patients with glioblastoma the mean values of all five metabolite ratios (i.e. tNAA/tCr, tCho/tNAA, tCho/tCr, Lac/tCr, and lip/Lac) were significantly different (Tab. 1). The tNAA/tCr ratio was significantly higher in the healthy tissue compared to other regions and on the contrary, the significantly lower values were found in the middle part of the tumor. No significant diferences in these metabolite ratios were observed between the peritumoral edema and solid part of tumors. For the tCho/tNAA ratio, all pairs of studied brain areas demonstrated significant differences with decreasing value from the middle part of the tumor through its solid part, edema up to the healthy brain tissue. The healthy brain tissue appeared to be significantly decreased in the $\mathrm{tCho} / \mathrm{tCr}$ ratio compared to other examined areas. The middle and solid tumor parts did not differ significantly. Peritumoral edema showed significantly lower values of this metabolite ratio than the solid tumor part, but with respect to the tumor center, the significance was not confirmed. The lowest values of the $\mathrm{Lac} / \mathrm{tCr}$ among all investigated brain areas were observed in the healthy tissue, taking into account that the only nonsignificant differences were related to the peritumoral 


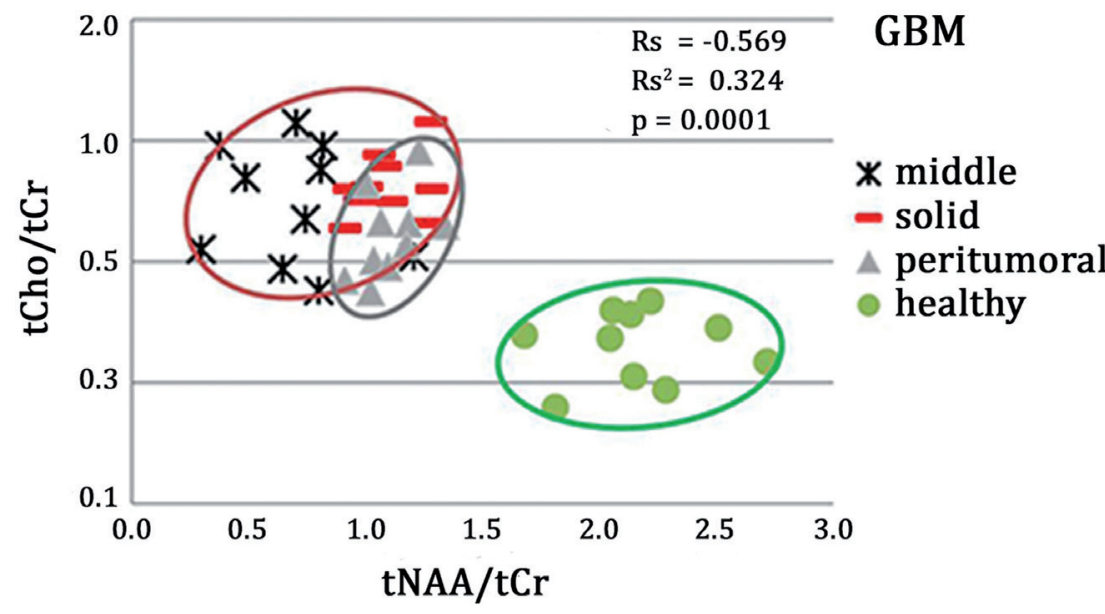

Figure 2. Correlation analysis of $\mathrm{tCho} / \mathrm{tCr}$ and $\mathrm{tNAA} / \mathrm{tCr}$ with respect to brain tissue area. Corelation of choline and $\mathrm{N}$-acetylaspartate to creatine ratios ( $\mathrm{tCho} / \mathrm{tCr}$ and tNAA/tCr) with respect to selected area in glioblastoma-affected brain tissue (GBM, $n=10$ ): middle of the tumorous mass (black crosses), solid tumor part (red dashes), peritumoral edema (gray triangles), and healthy tissue (green spheres). They are distinguished group of values pertaining to healthy tissue (circled in green), tumor tissue (circled in red) and peritumoral edema (circled in gray). Spearman correlation showed a significant negative dependence $(R=-0.569$, $p=0.0001)$. edema. However, within the glioblastoma-affected tissue, the significant differences in this metabolite ratio did not manifest. The lip/Lac ratio was significantly higher in the middle of the tumor than in any other brain areas, among which significant differences were not observed. Finally, using the Spearman correlation analysis, we found a statistically significant inverse relationship $(\mathrm{R}=-0.569, p=0.0001)$ between $\mathrm{tCho} / \mathrm{tCr}$ and $\mathrm{tNAA} / \mathrm{tC}$ ratios regarding the selected tissue area - from the healthy brain tissue, through peritumoral area, its solid part up to the central tumor mass (Fig. 2).

\section{Discussion}

Glioblastomas are usually described as intracranial tumors with quantitatively the highest rate of carcinogenesis and angiogenesis (Law 2009; Wijnen 2010; Kao et al. 2013). According to the literature, the typical glioblastomas manifestatio $n$ is

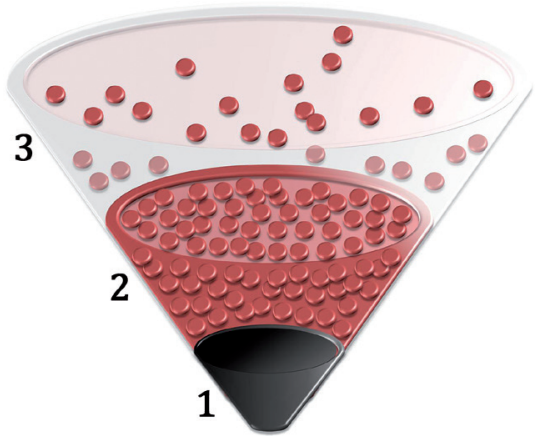

Figure 3. Scheme of cell density of glioblastoma based on ${ }^{1} \mathrm{H}$ MRSI. Schematic representation of the cell density and infiltrating character of glioblastomas based on ${ }^{1} \mathrm{H}$ MRSI examination in selected brain areas: in the middle of the tumor (1), in the solid part of the tumor (2), and in peritumoral edema (3). The gray color represents tissue necrosis, red dots glioblastomas cells. a high tumor cells proliferation and thus also increased density of cell membranes in tumorous tissue area (Lupo et al. 2007; Schneider et al. 2010; Marie and Shinjo 2011). Membrane phospholipids are beneficial for spectroscopic tumor detection. They perform important function as intracellular second messengers involved in the regulation of cell differentiation and proliferation (Wijnen 2010; Ha et al. 2013). Unfortunately, using the in vivo ${ }^{1} \mathrm{H}$ MRS it is not possible to directly evaluate these phospholipids due to their incorporation in the cell membranes (Soares and Law 2009; Barker 2010). Their examination would require extraction of the membrane and the application of organic solvents, which would allow to distinguish at least the major human brain phospholipids including phosphatidylcholine, phosphatidylserine, sphingomyelin, phosphatidylinositol, and phosphatidylethanolamine (Garett and Grisham 2008; Kornienko and Pronin 2009). However, it is possible to spectroscopically measure precursors of their synthesis and products of their degradation as the tCho signal contributors (Solivera and Law 2009; Ha et al. 2013). Since the level of tCho particularly reflects the concentration of phosphocholine which is more than twice increased in highgrade gliomas (Lupo et al. 2007; McKnight and Wladman 2010), tCho is suitable for monitoring tumor carcinogenesis (Guillevin et al. 2008; Housni and Boujraf 2013). In previous study it was reported that the $45 \%$ increase of tCho indicates tumor progression, while an increase of up to $35 \%$ indicates its stable status (Pinker et al. 2012). The direct correlation was also declared between the tCho/tNAA, tCho/tCr and the proliferation marker Ki-67 (Guillevin et al. 2008; Toyooka et al. 2008) which is a predictor of aggressive clinical tumor manifestation (Horska and Barker 2010; Kao et al. 2013). In this study, in addition to elevated values of $\mathrm{tCho} / \mathrm{tCr}$ and tCho/tNAA decreased levels of tNAA/tCr were also observed in glioblastoma-affected brain tissue compared to the healthy areas. Furthermore, based on the corelation analysis the relationship between decreasing $\mathrm{tNAA} / \mathrm{tCr}$, increasing $\mathrm{tCho} / \mathrm{tCr}$ values and the growing tumorus tissue was shown, thus from 
the healthy brain tissue through peritumoral area, tumorous solid part up to its middle core. However, the differences in tCho/tCr levels in marginal tumor area compared to its central part were not noticeable. It was declared, that in a necrotic part of glioblastomas in addition to the significant neuronal loss (Kornienko and Pronin 2009; McKnight and Wladman 2010; Kumar et al. 2012) also the process of tumor cell proliferation inhibited (Laprie et al. 2008; Wright et al. 2009), leading to the decreased concentration of tCho compared to the tumor mass (Callot et al. 2008; Pinker et al. 2012). Furthermore, it appears that the decrease of tNAA concentration correlates with the extent of tisue necrosis (Lai et al. 2008; Kornienko and Pronin 2009). There is a theory suggesting that due to the growing tumor the neovasculature could not sufficiently supply the more distant cells, resulting in hypoxic or almost necrotic regions, particularly in the central part of tumors (Lupo et al. 2007; Garett and Grisham 2008; Ganapathy et al. 2009). As a consequence spectroscopically detectable lipids could be present in these regions (Lai et al. 2008; Delikatny et al. 2011). In this study increased value of lip/Lac ratio was found suggesting the central tumor necrosis. However, the considerable variance of this ratio, esspecially in the middle part of the glioblastomas, suggested a diverse range of necrosis in individual tumors. As mentioned in literature, the high tissue heterogeneity is typical for glioblastomas, with the occurrence of low-aggressive even high-proliferating zones and central necrosis (Lai et al. 2008; Laprie et al. 2008; Schneider et al. 2010). The high-grade of malignancy in glioblastomas is further associated with significant changes at the cellular level. It leads to the suppression of mitochondrial function as centers of apoptotic regulations (Frezza and Gottlieb 2009; Ordys et al. 2010), resulting in changes in glycolysis, Krebs cycle, as well as in oxidative phosphorylation (DeBerardinis et al. 2008; Hsu and Sabatini 2008). However, not all cancer cells have impaired mitochondrial function (Kroemer and Pouyssegur 2008; Cairns et al. 2011) and despite of that only about $10 \%$ of the glycolytic pyruvate enters the Krebs cycle (de Souza et al. 2011). The reason is that for tumor metabolism could be a typical so-called Warburg effect, when cells prefer anaerobic rather than aerobic glycolysis, despite the sufficient presence of oxygen (DeBerardinis et al. 2008; Hsu and Sabatini 2008; Marie and Shinjo 2011). This deficiency is compensated by overexpression of glucose transporters leading to 20- to 30-fold increased import of glucose into the tumorous cell (Ganapathy et al. 2009), higher expression and activity of glycolytic enzymes, especially of hexokinase, phosphofructokinase and pyruvate kinase (Diaz-Ruiz et al. 2009; Ordys et al. 2010; Cairns et al. 2011), resulting in 30-fold acceleration of glycolysis (Ganapathy et al. 2009). Moreover, it was found that the functional rate of anaerobic glycolysis under aerobic conditions not only correlates with the degree of malignancy, but it is also associated with resistance to chemotherapy and radiotherapy (Kroemer and Pouyssegur
2008; de Souza et al. 2011). These changes are further accompanied by increased inhibition of mitochondrial metabolism, i.e. reactions in Krebs cycle as well as in respiratory chain (Diaz-Ruiz et al. 2009; Frezza and Gottlieb 2009), and ultimately, by greather production of lactate (Cairns et al. 2011; Glunde and Bhujwalla 2011). A significant increase of Lac/ tCr ratio was found also in this study. The elevation of this ratio was observed in the whole tumorous mass, i.e. in the middle as well as in the solid part of glioblastomas, indicated a substantial conversion of aerobic to anaerobic metabolism. In addition, the lactate formation in peritumoral area was only slightly below the level detected in tumors and seemed thus, that glioblastomas influence also the metabolism of the surrounding tissue. In this study, it was in agreementwith the Spearman corelation analysis of $\mathrm{tCho} / \mathrm{tCr}$ and $\mathrm{tNAA} / \mathrm{tCr}$ ratios with regard to selected brain areas. It was not possible to clearly distinguish the peritumoral area from the tumorous mass demonstrating similar levels of these metabolite ratios in these areas. However, the middle part of glioblastomas had in general lower values of tNAA/tCr compared to its solid or peritumoral regions, they did not differ significantly from each other. This indicated an infiltrating character of the tumor cells, which is in compliance with the published characteristics of glioblastomas (Lai et al. 2008; Law 2009; Wright et al. 2009). Using this clinically feasible ${ }^{1} \mathrm{H}$ MRSI evaluated at 1.5 Tesla it was possible to demonstrate high heterogeneity of glioblastomas, with necrotic middle part, highly proliferating solid part, metabolically influenced surrounding tissue with infiltrating tumorous cells (Fig. 3). In this study we showed that the ${ }^{1} \mathrm{H}$ MRS provides the noninvasive information about the extent of carcinogenesis, tumor expansion or necrotization and thus it could be helpful for intracranial tumors monitoring and treatment planning.

Acklowledgment. This publication was supported by "Biomedical Center Martin” (ITMS: 26220220187) and by the projects of Slovak Research and Development Agency (APVV-14-0088) and "CENTER OF TRANSLATIONAL MEDICINE“ (ITMS: 26220220021), co-funded from the Operational Programme Research and Innovation of ERDF and EU sources.

\section{References}

Barker P. B. (2010): Fundamentals of MR spectroscopy. In: Clinical MR Neuroimaging: Physiological and Functional Techniques. (Eds. J. H. Gillard, A. D. Waldman and P. B. Barker), pp. 5-20, Cambridge University Press, Cambridge

Cairns R. A., Harris I. S., Mak T. W. (2011): Regulation of cancer cell metabolism. Nat. Rev. Cancer 11, 85-95 https://doi.org/10.1038/nrc2981

Callot V., Galanaud D., Le Fur Y., Confort-Gouny S., Ranjeva J. P., Cozzone P. J. (2008): (1)H MR spectroscopy of human brain tumours: a practical approach. Eur. J. Radiol. 67, 268-274 https://doi.org/10.1016/j.ejrad.2008.02.036 
de Souza A. C., Justo G. Z., de Araujo D. R., Cavagis A. D. (2011): Defining the molecular basis of tumor metabolism: a continuing challenge since Warburg's discovery. Cell. Physiol. Biochem. 28, 771-792 https://doi.org/10.1159/000335792

DeBerardinis R. J., Lum J. J., Hatzivassiliou G., Thompson C. B. (2008): The biology of cancer: metabolic reprogramming fuels cell growth and proliferation. Cell Metab. 7, 11-20 https://doi.org/10.1016/j.cmet.2007.10.002

Delikatny E. J., Chawla S., Leung D. J., Poptani H. (2011): MRvisible lipids and the tumor microenvironment. NMR Biomed. 24, 592-611 https://doi.org/10.1002/nbm.1661

Diaz-Ruiz R., Uribe-Carvajal S., Devin A., Rigoulet M. (2009): Tumor cell energy metabolism and its common features with yeast metabolism. Biochim. Biophys. Acta 1796, 252-265 https://doi.org/10.1016/j.bbcan.2009.07.003

Frezza C., Gottlieb E. (2009): Mitochondria in cancer: not just innocent bystanders. Semin. Cancer Biol. 19, 4-11 https://doi.org/10.1016/j.semcancer.2008.11.008

Ganapathy V., Thangaraju M., Prasad P. D. (2009): Nutrient transporters in cancer: relevance to Warburg hypothesis and beyond. Pharmacol. Ther. 121, 29-40 https://doi.org/10.1016/j.pharmthera.2008.09.005

Garett R. H., Grisham C. M. (2008): Biochemistry. Brooks Cole, California

Glunde K., Bhujwalla Z. M. (2011): Metabolic tumor imaging using magnetic resonance spectroscopy. Semin. Oncol. 38, 26-41 https://doi.org/10.1053/j.seminoncol.2010.11.001

Guillevin R., Menuel C., Duffau H., Kujas M., Capelle L., Aubert A., Taillibert S., Idbaih A., Pallud J., Demarco G. et al. (2008): Proton magnetic resonance spectroscopy predicts proliferative activity in diffuse low-grade gliomas. J. Neurooncol. 87, 181-187 https://doi.org/10.1007/s11060-007-9508-y

Ha D. H., Choi S., Oh J. Y., Yoon S. K., Kang M. J., Kim K. U. (2013): Application of 31P MR spectroscopy to the brain tumors. Korean J. Radiol. 14, 477-486 https://doi.org/10.3348/kjr.2013.14.3.477

Horska A., Barker P. B. (2010): Imaging of brain tumors: MR spectroscopy and metabolic imaging. Neuroimaging Clin. N. Am. 20, 293-310 https://doi.org/10.1016/j.nic.2010.04.003

Housni A., Boujraf S. (2013): Multimodal magnetic resonance imaging in the diagnosis and therapeutical follow-up of brain tumors. Neurosciences (Riyadh) 18, 3-10

Hsu P. P., Sabatini D. M. (2008): Cancer cell metabolism: Warburg and beyond. Cell 134, 703-707 https://doi.org/10.1016/j.cell.2008.08.021

Kao H. W., Chiang S. W., Chung H. W., Tsai F. Y., Chen C. Y. (2013): Advanced MR imaging of gliomas: an update. Biomed. Res. Int. 2013, 970586 https://doi.org/10.1155/2013/970586

Kornienko V. N., Pronin I. N. (2009): Neuroradiology: history and new research technologies. In: Diagnostic Neuroradiology. (Eds. V. N. Kornienko and I. N. Pronin), pp. 1-27, Springer Berlin Heidelberg

Kroemer G., Pouyssegur J. (2008): Tumor cell metabolism: cancer's Achilles' heel. Cancer Cell. 13, 472-482 https://doi.org/10.1016/j.ccr.2008.05.005

Kumar V., Sharma U., Jagannathan N. R. (2012): In vivo magnetic resonance spectroscopy of cancer. Biomedical Spectroscopy and Imaging $\mathbf{1}, 89-100$

Lai P. H., Weng H. H., Chen C. Y., Hsu S. S., Ding S., Ko C. W., Fu J. H., Liang H. L., Chen K. H. (2008): In vivo differentiation of aerobic brain abscesses and necrotic glioblastomas multiforme using proton MR spectroscopic imaging. AJNR Am. J. Neuroradiol. 29, 1511-1518

https://doi.org/10.3174/ajnr.A1130

Laprie A., Catalaa I., Cassol E., McKnight T. R., Berchery D., Marre D., Bachaud J. M., Berry I., Moyal E. C. (2008): Proton magnetic resonance spectroscopic imaging in newly diagnosed glioblastoma: predictive value for the site of postradiotherapy relapse in a prospective longitudinal study. Int. J. Radiat. Oncol. Biol. Phys. 70, 773-781

https://doi.org/10.1016/j.ijrobp.2007.10.039

Law M. (2009): Advanced imaging techniques in brain tumors. Cancer Imaging. 9 Spec No A, S4-9 https://doi.org/10.1102/1470-7330.2009.9002

Lupo J. M., Cha S., Chang S. M., Nelson S. J. (2007): Analysis of metabolic indices in regions of abnormal perfusion in patients with high-grade glioma. AJNR Am. J. Neuroradiol. 28, 1455-1461 https://doi.org/10.3174/ajnr.A0586

Marie S. K., Shinjo S. M. (2011): Metabolism and brain cancer. Clinics (Sao Paulo, Suppl. 1) 66, 33-43

McKnight T. R., Wladman A. D. (2010): Magnetic resonance spectroscopy in adult neoplasia. In: Clinical MR Neuroimaging: Physiological and Functional Techniques (Eds. J. H. Gillard, A. D. Waldman and P. B. Barker), pp. 295-312, Cambridge University Press, Cambridge

Opstad K. S., Bell B. A., Griffiths J. R., Howe F. A. (2008): An investigation of human brain tumour lipids by high-resolution magic angle spinning $1 \mathrm{H}$ MRS and histological analysis. NMR Biomed. 21, 677-685 https://doi.org/10.1002/nbm.1239

Ordys B. B., Launay S., Deighton R. F., McCulloch J., Whittle I. R. (2010): The role of mitochondria in glioma pathophysiology. Mol. Neurobiol. 42, 64-75 https://doi.org/10.1007/s12035-010-8133-5

Pinker K., Stadlbauer A., Bogner W., Gruber S., Helbich T. H. (2012): Molecular imaging of cancer: MR spectroscopy and beyond. Eur. J. Radiol. 81, 566-577 https://doi.org/10.1016/j.ejrad.2010.04.028

Schneider T., Mawrin C., Scherlach C., Skalej M., Firsching R. (2010): Gliomas in adults. Dtsch. Arztebl. Int. 107, 799-807

Soares D. P., Law M. (2009): Magnetic resonance spectroscopy of the brain: review of metabolites and clinical applications. Clin. Radiol. 64, 12-21 https://doi.org/10.1016/j.crad.2008.07.002

Solivera J., Cerdan S., Pascual J. M., Barrios L., Roda J. M. (2009): Assessment of 31P-NMR analysis of phospholipid profiles for potential differential diagnosis of human cerebral tumors. NMR Biomed. 22, 663-674 https://doi.org/10.1002/nbm.1387

Toyooka M., Kimura H., Uematsu H., Kawamura Y., Takeuchi H., Itoh H. (2008): Tissue characterization of glioma by proton magnetic resonance spectroscopy and perfusion-weighted 
magnetic resonance imaging: glioma grading and histological correlation. Clin. Imaging 32, 251-258

https://doi.org/10.1016/j.clinimag.2007.12.006

Walther T. C., Farese R. V., Jr. (2009): The life of lipid droplets. Biochim. Biophys. Acta 1791, 459-466

https://doi.org/10.1016/j.bbalip.2008.10.009

Wijnen J. P. (2010): Multi-nuclear Magnetic Resonance Spectroscopy of Human Brain Tumours. GVO drukkers \& vormgevers B.V., Ponsen \& Looijen, Nijmegen
Wright A. J., Fellows G., Byrnes T. J., Opstad K. S., McIntyre D. J., Griffiths J. R., Bell B. A., Clark C. A., Barrick T. R., Howe F. A. (2009): Pattern recognition of MRSI data shows regions of glioma growth that agree with DTI markers of brain tumor infiltration. Magn. Reson. Med. 62, 1646-1651 https://doi.org/10.1002/mrm.22163

Received: March 30, 2017

Final version accepted: July 6, 2017 